\title{
OPEN Cat-CrNP as new material with catalytic properties for 2-chloro-2-propen-1-ol and ethylene oligomerizations
}

\author{
Jacek Malinowski ${ }^{1}$, Dagmara Jacewicz ${ }^{1}$, Artur Sikorski ${ }^{1}$, Mariusz Urbaniak ${ }^{2}$, \\ Przemysław Rybiński ${ }^{2}$, Patrycja Parnicka ${ }^{1}$, Adriana Zaleska-Medynska ${ }^{1}$, \\ Barbara Gawdzik ${ }^{2 \bowtie}$ \& Joanna Drzeżdżon ${ }^{1}$
}

The contemporary search for new catalysts for olefin oligomerization and polymerization is based on the study of coordinating compounds and/or organometallic compounds as post-metallocene catalysts. However known catalysts are suffered by many flaws, among others unsatisfactory activity, requirement of high pressure or instability at high temperatures. In this paper, we present a new catalyst i.e. the crystalline complex compound possesing high catalytic activity in the oligomerization of olefins, such as 2-chloro-2-propen-1-ol and ethylene under very mild conditions (room temperature, 0.12 bar for ethylene oligomerization, atmospheric pressure for 2-chloro-2-propen-1-ol oligomerization). New material-Cat-CrNP ([nitrilotriacetato-1,10-phenanthroline]chromium(III) tetrahydrate) has been obtained as crystalline form of the nitrilotriacetate complex compound of chromium(III) with 1,10-phenanthroline and characterized in terms of its crystal structure by the XRD method and by multi-analytical investigations towards its physicochemical propeties The yield of catalytic oligomerization over Cat-CrNP reached to $213.92 \mathrm{~g} \cdot \mathrm{mmol}^{-1} \cdot \mathrm{h}^{-1} \cdot \mathrm{bar}^{-1}$ and $3232 \mathrm{~g} \cdot \mathrm{mmol}^{-1}$. $\mathrm{h}^{-1} \cdot \mathrm{bar}^{-1}$ for the 2-chloro-2-propen-1-ol and ethylene, respectively. Furthemore, the synthesis of CatCrNP is cheap, easy to perform and solvents used during preparation are environmentally friendly.

Since the 1990s, when post-metallocene catalysts were invented, research into polymerization catalysts and material and polymer products became more popular and carried out with greater intensity ${ }^{1,2}$. Nowadays, new materials are sought to act as catalysts for olefin polymerization and oligomerization ${ }^{3-5}$.

Philips catalyst, created by depositing chromium(VI) on silica gel with an oxide, is one of the most commonly used catalysts for the polymerization of olefin, next to Ziegler-Natta catalysts ${ }^{6}$. For many years, Philips type catalysts have been modified in order to obtain polyolefins with the desired properties ${ }^{6}$. The modifications of the Philips catalyst are based on chromium(V) oxide, chromium(III) oxide and chromium(II) oxide. The Philips catalyst is also used in the nanocarrier which is alumina. The common element in between the modification of the Philips catalyst and the post-metallocene chromium(III) catalysts is noticeable. New postmetallocene catalysts are often activated by modified methylaluminoxane, which contains significant amounts of aluminum ${ }^{6}$. Chromium(III) complex compounds are known as highly active catalysts for olefin oligomerization and polymerization ${ }^{6}$. The chromium(III) cation can be stabilized by various multi-donor ligands such as, for example, $\mathrm{N}$-pyrrolidine pendant donor or $N, N, N$-bis(imino)trihydroquinoline ${ }^{7,8}$. Chromium(III) complex with chloride and $N, N, N$-bis(imino) trihydroquinoline is used as precatalyst and it must be activated by modified methylaluminoxane $(\mathrm{MMAO})^{8}$. The mentioned chromium(III) complex upon activation is used for the polymerization of ethylene at $80^{\circ} \mathrm{C}$ degrees for $1 \mathrm{~h}$. The product of the polymerization reaction using this catalytic system is polyethylene. One of the possible four-donor ligand which stabilizes metal ions is nitrilotriacetate anion. Amine nitrilotriacetate salts e.g. di-n-butylamine salt of nitrilotriacetic acid are used for removal copper catalyst from poly(2,6-dimethyl-1,4-phenylene oxide $)^{9}$, however, according to our best knowledge, there is no reports on the catalytic properties of chromium(III) complex compounds with the nitrilotriacetate anion for oligomerization and polymerization. In addition, nitrilotriacetic acid $\left(\mathrm{H}_{3} \mathrm{NTA}\right)$ was used in the synthesis of polymers in such a way that nitrilotriacetate $\mathrm{Ni}(\mathrm{II})$ complex end-functionalized polystyrene was obtained ${ }^{10}$. The nitrilotriacetate 


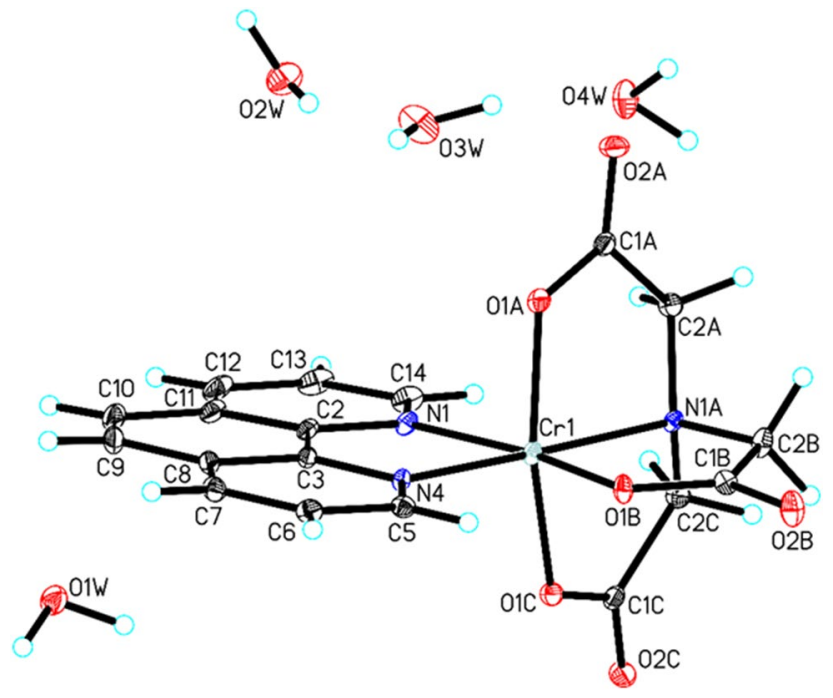

Figure 1. Molecular structure of title compound, showing the atom-labelling scheme (hydrogen bonds are represented by dashed lines).

polymer material has been developed and prepared for use in controlled bioconjugation ${ }^{11-13}$. The complexes of transition metal cations containing a nitrilotriacetate anion are used for the purification and detection of proteins, provided that they have been tagged with oligohistidine ${ }^{14-16}$.

Nitrilotriacetate complexes with $\mathrm{Mg}^{2+}, \mathrm{Ca}^{2+}, \mathrm{Sr}^{2+}, \mathrm{Ba}^{2+}$ are used as coordination polymers for self-templating porous carbon electrocatalysts ${ }^{17-20}$. Crystalline complex compounds containing nitrilotriacetate anion and cations: $\mathrm{Mg}^{2+}, \mathrm{Ca}^{2+}, \mathrm{Sr}^{2+}, \mathrm{Ba}^{2+}$ were pyrolyzed at $750{ }^{\circ} \mathrm{C}$ in $\mathrm{Ar}$ atmosphere. Inorganic particles formed during pyrolysis were tested. These particles are, for example, $\mathrm{MgO}, \mathrm{BaCO}_{3}$ which are carbon-deposited. These investigations allow to understanding the role of metal ions: $\mathrm{Mg}^{2+}, \mathrm{Ca}^{2+}, \mathrm{Sr}^{2+}, \mathrm{Ba}^{2+}$ in the formation of morphological diversity of the carbons which constitute electrocatalysts for reduction of oxygen ${ }^{21}$.

The first post-metallocene catalysts were nickel(II) and palladium(II) complex compounds with diimine ligands, which catalyzed the reaction of polyethylene formation. Brookhart and co-workers were pioneers in the design and research of post-metallocene catalysts ${ }^{22}$. The literature shows that modifications of these catalysts are often researched and used in olefin polymerization and copolymerization ${ }^{23}$. The modification of the ligand structure and the optimization of the conditions of the polymerization and copolymerization process have a significant impact on the catalytic activity of these complexes. These complexes allow a controlled influence on the microstructure of polymer chains ${ }^{23}$. Currently designing new nickel(II) catalysts, attention is paid to the ring-deformation of ligands ${ }^{24}$. Literature reports that modified diimine complexes of palladium(II) found their application in the "living" polyglass, however, due to the attachment of only one chain to the metal, industrial application of these test results is very difficult ${ }^{25}$.

Pioneering research in the field of iron and cobalt compounds-based catalysts with bis (arylimino) pyridine ligands was carried out by an independent group of Brookhart and Gibson ${ }^{26,27}$. Iron and cobalt complexes are also used as catalysts for ethylene oligomerization and polymerization. The development of the research conducted this day indicates a large influence of the deformation of the ligand ring on the catalytic activity ${ }^{28}$.

Currently, homogeneous chromium(III) precatalysts used for the oligomerization of ethylene are known. Most often these are catalysts containing bidentate ligands of the $\mathrm{N}^{\wedge} \mathrm{P}, \mathrm{N}^{\wedge} \mathrm{O}$ and $\mathrm{N}^{\wedge} \mathrm{N}$ type, tridentate $\mathrm{N}^{\wedge} \mathrm{N}^{\wedge} \mathrm{N}$, $\mathrm{N}^{\wedge} \mathrm{N}^{\wedge} \mathrm{O}, \mathrm{N}^{\wedge} \mathrm{O}^{\wedge} \mathrm{N}$ type and tetrahedral ligands $\mathrm{N}^{\wedge} \mathrm{N}^{\wedge} \mathrm{N}^{\wedge} \mathrm{N}$ type ${ }^{29}$. Chromium(III) complex compounds are characterized by moderate activity in ethylene oligomerization at the temperature of the experiment within the range of $35-75^{\circ} \mathrm{C}^{29}$.

In this work, new material possessing catalytic properties for 2-chloro-2-propen-1-ol and ethylene oligomerizations was successfully synthesized. Cat-CrNP is newly obtained nitrilotriacetate complex compound of chromium(III) with 1,10-phenanthroline ([nitrilotriacetato-1,10-phenanthroline] chromium(III) tetrahydrate). The nitrilotriacetate chromium(III) complex has been fully characterized by methods: XRD, elemental analysis, IR, MALDI-TOF-MS, potentiometric and conductometric titrations, thermal analysis and scanning electron microscopy. For the first time Cat-CrNP was used as a precatalyst with methylaluminoxane (MMAO-12) as an activator for the oligomerization of 2-chloro-2-propen-1-ol and ethylene.

\section{Results and discussion}

Cat-CrNP has been tested and characterized towards its physicochemical properties by multi analytical methods such as XRD, elemental analysis, IR, MALDI-TOF-MS, potentiometric conductometric titrations, thermal analysis and scanning electron microscopy. Cat-CrNP is new nitrilotriacetate complex compound of chromium(III) with 1,10-phenanthroline (Fig. 1). 


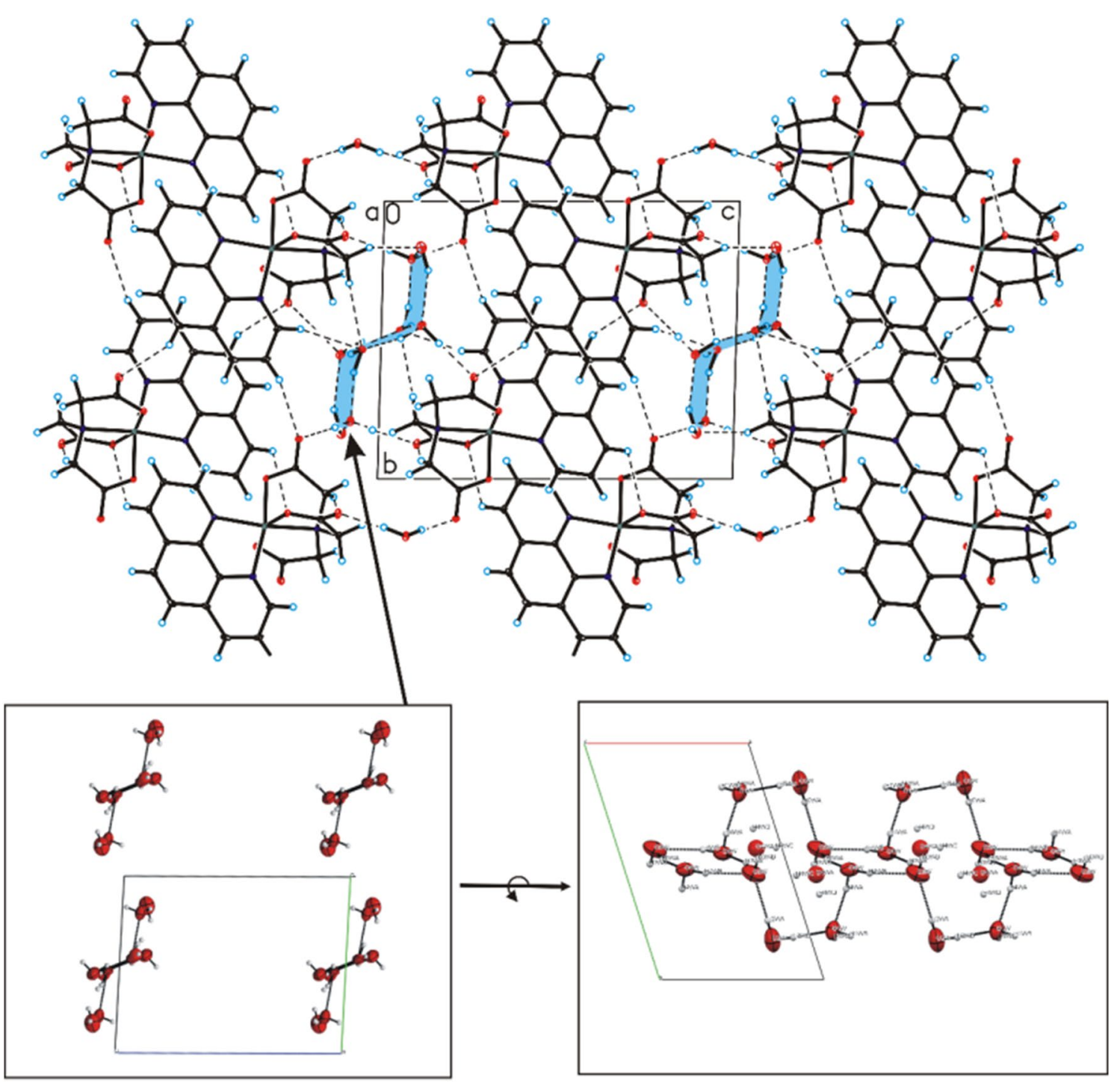

Figure 2. Crystal packing of (nitrilotriacetato-1,10-phenanthroline)chromium(III) tetrahydrate viewed along $a$-axis.

The title compound has an interesting structure. Cat-CrNP was obtained as violet-gold crystals. In the crystal of title compound, molecules of nitrilotriacetate complex compound of chromium(III) with 1,10-phenanthroline are linked via $\mathrm{C}-\mathrm{H} \ldots \mathrm{O}$ hydrogen bonds and $\pi-\pi$ interactions to produce blocks along b-axis, whereas water molecules interact via $\mathrm{O}_{\text {(water) }}-\mathrm{H}_{\cdots} \mathrm{O}_{\text {(water) }}$ interactions to form a centrosymmetric, alternately arranged $\left(\mathrm{H}_{2} \mathrm{O}\right)_{4}$ (cyclic-planar, tetrameric 0-4-A structure) and $\left(\mathrm{H}_{2} \mathrm{O}\right)_{8}$ (cyclic-chair, octameric 0-8-I structure) water clusters, which produce tapes extending along a-axis ${ }^{30-32}$. In the crystal packing, the adjacent blocks and tapes are connected through $\mathrm{C}-\mathrm{H} \cdots \mathrm{O}_{\text {(water) }}$ and $\mathrm{O}_{\text {(water) }}-\mathrm{H} \cdots \mathrm{O}$ hydrogen bonds to form a 3D framework structure (Fig. 2).

Elemental analysis of as-prepared Cat-CrNP revealed that it is composed of C (44.18\%), H (4.51\%) and N (8.54\%). Anal. Calcd.: C, 43.91\%, H, 4.51\%, N, 8.53\%. Thus, experimentally determined composition of the chromium(III) complex compound perfectly fits theoretical findings.

The IR analysis showed that medium intensity stretch band from carboxylic acid occurs at $3440 \mathrm{~cm}^{-1}$. In the range $2970-2939 \mathrm{~cm}^{-1} \mathrm{O}-\mathrm{H}$ stretching vibrations of crystallization water are observed. The range $1685-1664 \mathrm{~cm}^{-1}$ confirms the presence of $\mathrm{C}=\mathrm{O}$ stretching of the carbonyl group. The peak at $445 \mathrm{~cm}^{-1}$ corresponds to deformation vibrations $\mathrm{Cr}-\mathrm{N}$.

MALDI-TOF-MS revealed that Cat-CrNP fragments into M-COO (the peak at 444,052 m/z) and M-COOH (the peak at $443,037 \mathrm{~m} / \mathrm{z}$ ). The potentiometric titration has been used to investigate the stability of the title complex compound by Hyperquad program. The value of the $\log \beta$ for Cat-CrNP equal to $8.97 \pm 0.05$. The value of the $\log \beta=8.97 \pm 0.05$ refers to the final complex compound containing the two ligands nitrilotriacetate anion and 1,10-phenanthroline. The fit of the experimental data to the mathematical model is shown in Fig. 4 in Supplementary Information. In this figure, in the legend on the right, you can see that the mathematical model uses an addition to the MLR system which corresponds to the final complex as M is $\mathrm{Cr}$ (III), L is a nitrilotriacetate anion and $\mathrm{R}$ is 1,10-phenanthroline. Fig. 4 in Supplementary Information shows that the fit of the experimental 

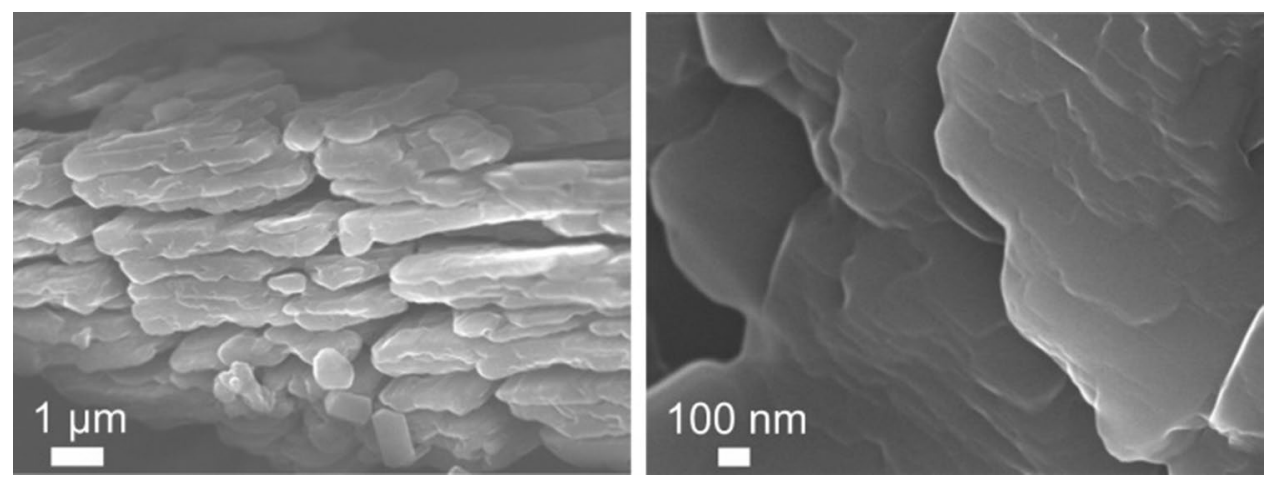

Figure 3. SEM images of Cat-CrNP complex.

values to the theoretical model is very good. The conductometric analysis allow to confirm the composition of the chromium(III) complex compound. The decrease in the conductivity of the solution is maintained to $\mathrm{n}_{\mathrm{NaOH}}: \mathrm{n}_{\mathrm{H}_{3} \mathrm{NTA}}=4$, then $\mathrm{n}_{\mathrm{NaOH}}: \mathrm{n}_{\mathrm{H}_{3} \mathrm{NTA}}>4$ there is an increase in conductivity. At $\mathrm{n}_{\mathrm{NaOH}}: \mathrm{n}_{\mathrm{H}_{3} \mathrm{NTA}}$ equal to 3 the conductivity of the solution is lowered due to the formation of the complex compound.

Cat-CrNP was subjected to thermal analysis using the thermogravimetric method. The analysis of the thermal decomposition of the coordination compound was carried out in the temperature range from $0{ }^{\circ} \mathrm{C}$ to $1000{ }^{\circ} \mathrm{C}$. Cat-CrNP undergoes thermal decomposition in 7 stages. Cat-CrNP is a tetrahydrate therefore TG/DTA analyses shows the thermal weight loss corresponding to the desorption of water at low temperature region. The first stage of decomposition reached the temperature of $80{ }^{\circ} \mathrm{C}$, where the weight loss was $8.23 \%$. In the first stage of thermal analysis, a peak is observed at $62.2^{\circ} \mathrm{C}$, where there was a weight loss of $2.68 \%$. The second stage of thermal decomposition occurred in the temperature range of $80^{\circ} \mathrm{C}$ to $140^{\circ} \mathrm{C}$, where a second peak is observed, weight loss $(1.23 \%)$ at $90.8^{\circ} \mathrm{C}$. The third stage of thermal analysis of Cat-CrNP occurs in the temperature range of $140-380^{\circ} \mathrm{C}$. The weight of the sample during the analysis in this temperature range decreased by $24.65 \%$. In further analysis of TG up to $440{ }^{\circ} \mathrm{C}$ a mass loss equal to $10.67 \%$ and a peak at $437.7^{\circ} \mathrm{C}$ is observed, where $2.38 \%$ of the sample mass has been decomposed. Then the sample decomposed in $10.67 \%$ to the temperature of $460^{\circ} \mathrm{C}$ and in the next stage by $35.94 \%$ to $660^{\circ} \mathrm{C}$. In the last stage of decomposition of the sample, the weight loss was $1.53 \%$. Finally, SEM analysis was used for catalysts morphology imaging. As it was shown in Fig. 3, the chromium complex exhibited a plate-like structure with regular edges and smooth surfaces.

Cat-CrNP has been used for the oligomerization of 2-chloro-2-propen-1-ol and ethylene. The oligomers obtained in the oligomerization of 2-chloro-2-propen-1-ol have been characterized by IR. Medium intensity stretch band of the $\mathrm{O}-\mathrm{H}$ group in the oligomer chain participating in hydrogen bonding occurs at $3475 \mathrm{~cm}^{-1}$. $\mathrm{CH}_{2}$ bending vibration in the oligomer chain is confirmed by peaks in the range $1457-1402 \mathrm{~cm}^{-1}$. C-O stretching vibration occurs at $1178 \mathrm{~cm}^{-1}$. C-Cl bending vibrations in the oligomer chain have been confirmed by the presence of the peak at $575 \mathrm{~cm}^{-1}$. MALDI-TOF-MS analysis showed that the oligomer sample contains from 4 to 7 mers in the chain. Moreover, the oligomers observed in MALDI-TOF-MS contain precatalyst. An appropriate isotope pattern for $\mathrm{Cr}^{52}$ and $\mathrm{Cr}^{53}$ which is observed on figures attached in Electronic Supplementary Information i.e. Figure 2 (MALDI-TOF-MS spectrum of Cat-CrNP) and also on Fig. 7 and 11 confirms it. In the case of MALDI-TOF-MS spectra of ethylene and 2-chloro-2-propen-1-ol oligomers the peaks $459 \mathrm{~m} / \mathrm{z}$ and $460 \mathrm{~m} / \mathrm{z}$ confirm this. The oligomerization product of 2-chloro-2-propenol was tested for thermal stability. The sample was decomposed in 5 stages. The first stage of decomposition of the sample resulted in a weight loss of $10.21 \%$ and it was recorded up to $140{ }^{\circ} \mathrm{C}$. A peak was recorded in the above-mentioned temperature range at a temperature of $101.1^{\circ} \mathrm{C}$, where the weight loss was $1.18 \%$. The second stage of thermal decomposition of the tested sample resulted in a weight loss of $5.91 \%$ in the temperature range of $140-200{ }^{\circ} \mathrm{C}$. In the third stage $24.62 \%$ of the sample decomposed in in the temperature range of $200-440^{\circ} \mathrm{C}$. In this interval, a peak was recorded at $236.0^{\circ} \mathrm{C}$ (weight loss $1.49 \%$ ). In the penultimate stage, the sample decomposed in $12.01 \%\left(440-750{ }^{\circ} \mathrm{C}\right)$, while in the last stage it was $2.37 \%\left(750-1000^{\circ} \mathrm{C}\right)$.

The analysis of samples obtained as a result of ethylene oligomerization confirmed the structure of the product obtained. IR spectrum allow to concluded that peaks at $2924 \mathrm{~cm}^{-1}$ confirms strong asymmetric $\mathrm{CH}_{2}$ stretching vibration in the chain of the oligomer. The peak at $2853 \mathrm{~cm}^{-1}$ correspond with strong symmetrical $\mathrm{CH}_{2}$ stretching vibration. The presence of strong deformations of $\mathrm{CH}_{2}$ in the oligomer chain is confirmed by the peak at $1514 \mathrm{~cm}^{-1}$. Peaks in the range $1468-1426 \mathrm{~cm}^{-1}$ allow to conclude that weak symmetrical deformation of the terminal $-\mathrm{CH}_{3}$ occurs in the oligomer chain. The peak at $857 \mathrm{~cm}^{-1}$ confirms the presence of $-\mathrm{CH}_{2}$ rocking vibration. MALDI-TOF-MS showed that the product of ethylene oligomerization contains from 12 to 24 mers. In order to understand thermal stability of the obtained oligomers, the sample of oligomers was subjected to the thermal analysis. The sample decomposes in 5 steps. In the first stage of $5.17 \%$ undergoes decomposition to $100^{\circ} \mathrm{C}$. Additionally a peak at $83.6^{\circ} \mathrm{C}$ was recorded, where the weight loss was $1.23 \%$. The second step of thermal analysis $\left(100-320^{\circ} \mathrm{C}\right)$ resulted in $27.83 \%$ weight loss of the sample. The peak at $149.5^{\circ} \mathrm{C}$ was recorded, where the sample weight decreased by $2.15 \%$. In the next stage of thermal analysis $\left(320-520^{\circ} \mathrm{C}\right)$ the sample decomposed by $9.38 \%$. The penultimate stage of the sample decomposition was recorded in the temperature range of $520-740^{\circ} \mathrm{C}$ (weight loss 6.68\%). In the last stage of sample decomposition, the sample decreased by $7.08 \%$. 

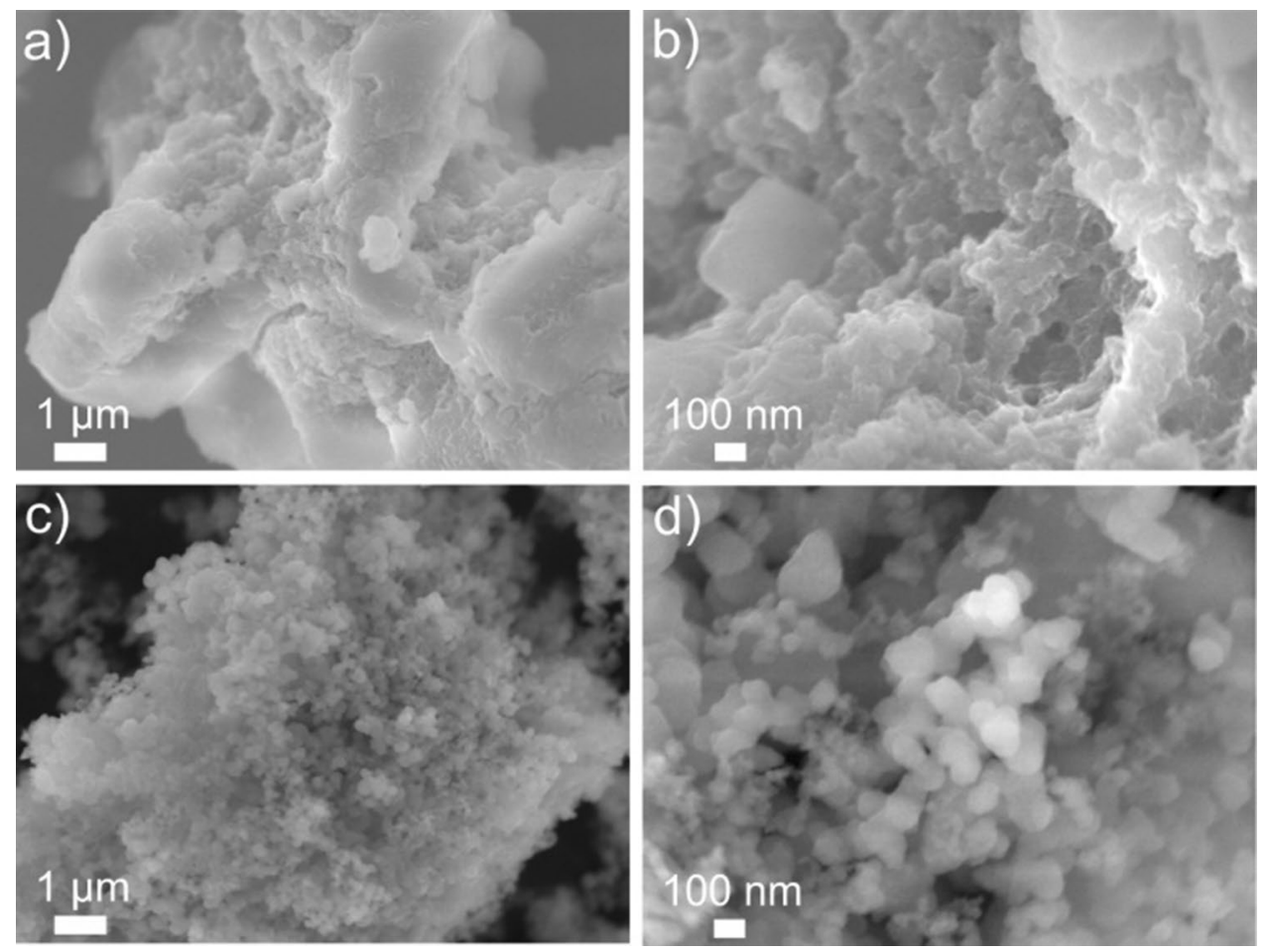

Figure 4. Low and high magnification SEM images of (a, b) 2-chloro-2-propen-1-ol, and (c, d) ethylene oligomers.

Glass transition temperatures were determined for the products of oligomerization of 2-chloro-2-propen-1-ol and ethylene by DSC method. In the case of a sample of the 2-chloro-2-propen-1-ol oligomerization product, the cooling curve records the thermal change $(\mathrm{Tg})$ at $-113^{\circ} \mathrm{C}$, and in the case of the heating curve at $\mathrm{T}=-95^{\circ} \mathrm{C}$. In the case of the ethylene oligomerization product sample, the cooling curve records the thermal change ( $\mathrm{Tg}$ ) at $-109^{\circ} \mathrm{C}$, and in the case of the heating curve at $\mathrm{T}=-91^{\circ} \mathrm{C}$.

The morphology of the 2-chloro 2-propen 1-ol and ethylene oligomers were investigated by SEM, and the results are shown in Fig. 4. SEM images show that oligomers presented small, highly coagulated, and nonuniform particles. According to the literature ${ }^{33,34}$, such a one-dimensional structure might physically provide a better dispersion in the monomers and better exposure of active sites to the reactants thus achieved high catalytic activity $^{33,34}$

The yield of catalytic oligomerization over Cat-CrNP equaled to $213.92 \mathrm{~g} \cdot \mathrm{mmol}^{-1} \cdot \mathrm{h}^{-1} \cdot \mathrm{bar}^{-1}$ and $3232 \mathrm{~g}$. $\mathrm{mmol}^{-1} \cdot \mathrm{h}^{-1} \cdot \mathrm{bar}^{-1}$ for the 2-chloro-2-propen-1-ol and ethylene, respectively. It means that Cat-CrNP is very highly active catalyst for the ethylene oligomerization and it is highly active catalyst for the 2-chloro-2-propen1-ol oligomerization (Figs. 5 and 6). Analyzing other chromium(III) complexes with catalytic properties in ethylene oligomerization (Fig. 5), it can be concluded that the Cat-CrNP-new catalytic material shows catalytic activity similar to the best precatalysts. Catalytic oligomerization of ethylene over Cat-CrNPs is only a slightly lower than that previously reported for $\left[\mathrm{Cr}(\text { dipic })_{2}\right] \mathrm{Hdmbipy} \cdot 2.5 \mathrm{H}_{2} \mathrm{O}\left(3232\right.$ and $3798 \mathrm{~g} \cdot \mathrm{mmol}^{-1} \cdot \mathrm{h}^{-1} \cdot \mathrm{bar}^{-1}$, respectively), nonetheless, synthesis of material reported in this work does not require the usage of thrichlormethane and methanol, and precipitation time was shortened from 2 months to 14 days. It should also be noted that the investigated oligomerization processes with the participation of the new material Cat-CrNP proceed in very mild conditions. Although other catalysts with higher catalytic activity values than the catalyst described in this work are known in the literature, but synthesis of Cat-CrNP is very simple, cheap and it crystallizes very quickly, comparing to synthesis procedure of commercially available catalysts. In addition, the synthesis uses mainly an environmentally friendly solvent-water.

Comparing the catalytic activity of the new precatalyst described in this work with the precatalysts used for the oligomerization of ethylene and being transition metal complex compounds with $\mathrm{N}^{\wedge} \mathrm{N}$ bidentate ligands, it can be concluded that Cat-CrNP exhibits outstanding catalytic activity. Iron(II) complex compounds with $\mathrm{N}^{\wedge} \mathrm{N}$ bidentate ligands, such as diimine $\left(\mathrm{Ph}_{2} \mathrm{C}=\mathrm{N}\right)_{2} \mathrm{C}_{2} \mathrm{H}_{4}$ ligand show low catalytic activity in the range from 100 to $550 \mathrm{~g} \cdot \mathrm{mmol}^{-1} \cdot \mathrm{h}^{-1} \cdot \mathrm{bar}^{-1}{ }^{41}$. Likewise nickel(II) complexes with $\mathrm{N}^{\wedge} \mathrm{N}$ bidentate ligands exhibit lower catalytic activity than Cat-CrNP. These nickel(II) complex compounds exhibit a maximum catalytic activity of $1638 \mathrm{~g} \cdot \mathrm{mmol}^{-1} \cdot \mathrm{h}^{-1} \cdot \mathrm{bar}^{-1}$ in ethylene oligomerization ${ }^{42}$. 


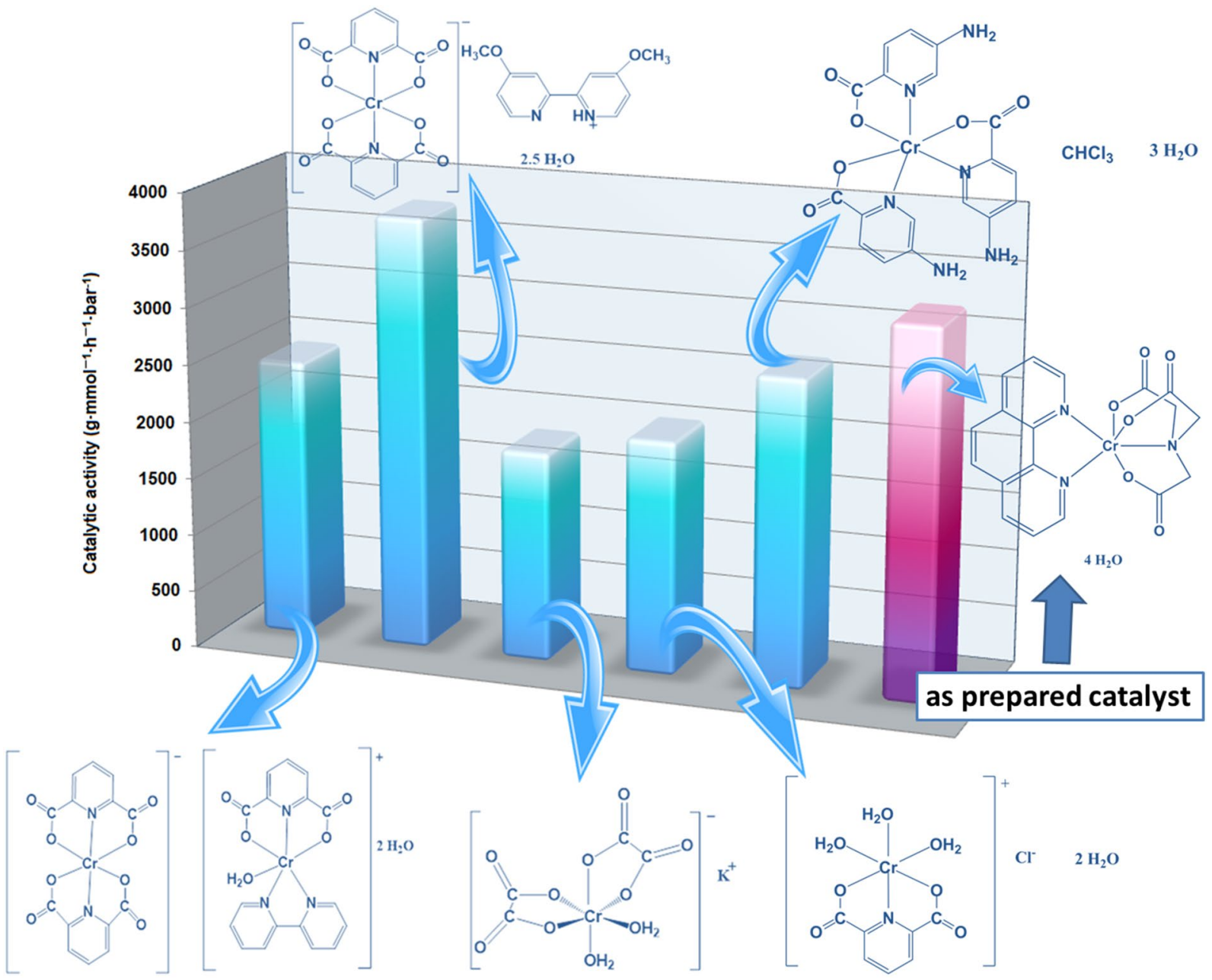

Figure 5. The catalytic activities of $\mathrm{Cr}$ (III) complexes for ethylene oligomerization based on $^{35}$.

\section{Conclusions}

This application brings a new concept of using a new coordination compound obtained in a crystalline form as a material with catalytic properties in the oligomerization of ethylene and 2-chloro-2-propen-1-ol. Physicochemical and catalytic properties of Cat-CrNP were fully described in this article. Cat-CrNP crystallizes in the triclinic system. It is thermally decomposed in 7 stages in the range $0{ }^{\circ} \mathrm{C}$ to $1000{ }^{\circ} \mathrm{C}$. While in the MALDITOF-MS analysis it fragmented into $\mathrm{M}$ minus $\mathrm{COO}$ and $\mathrm{M}$ minus $\mathrm{COOH}$. Cat-CrNP has high catalytic activity for 2-chloro-2-propen-1-ol and ethylene oligomerizations. The sample of the oligomerization products contains from 4 to 7 mers and from 12 to 24 mers for 2-chloro-2-propen-1-ol and ethylene oligomerizations, respectively. The results described in this article create the prospect of using the new material, Cat-CrNP, as a catalyst in the oligomerization and polymerization reactions of various olefins.

\section{Methods}

Synthetic procedures. Cat-CrNP synthesis. To a suspension of nitrilotriacetic acid $\left(0.57 \mathrm{~g}\right.$ in $\left.40 \mathrm{~mL} \mathrm{H}_{2} \mathrm{O}\right)$ was added an aqueous potassium hydroxide solution $\left(0.51 \mathrm{~g}\right.$ in $\left.10 \mathrm{~mL} \mathrm{H}_{2} \mathrm{O}\right)$ to convert the acid to a highly water soluble salt. An aqueous $\mathrm{CrCl}_{3}$ solution $(0.54 \mathrm{~g}$ in $10 \mathrm{~mL}$ of water) was added to the reaction solution. An ethanolic solution of 1,10-phenatroline $(0.54 \mathrm{~g}$ in $25 \mathrm{~mL}$ of ethanol) was then added. The entire process was carried out using a magnetic stirrer, and in the last step, the reaction solution was heated under reflux at a temperature of $50{ }^{\circ} \mathrm{C}$. Cat-CrNP crystallizes within 14 days. The molar mass of Cat-CrNP is equal to $492.38 \mathrm{~g} \cdot \mathrm{mol}^{-1}$ and the yield of the synthesis of the complexes is $68 \%$.

2-Chloro-2-propen-1-ol oligomerization. 2-Chloro-2-propen-1-ol was subjected to oligomerization under the following conditions: at room temperature, under atmospheric pressure, and under a nitrogen atmosphere. In the first oligomerization step, Cat-CrNP $(3 \mu \mathrm{mol})$ was dissolved in toluene $(2 \mathrm{~mL})$. Then MMAO-12 $(3 \mathrm{~mL})$ was added to the resulting toluene solution. In the last step, 2-chloro-2-propen-1-ol was slowly added. After 25 min of the reaction the gel product was formed. The final product obtained was dried and weighed. 


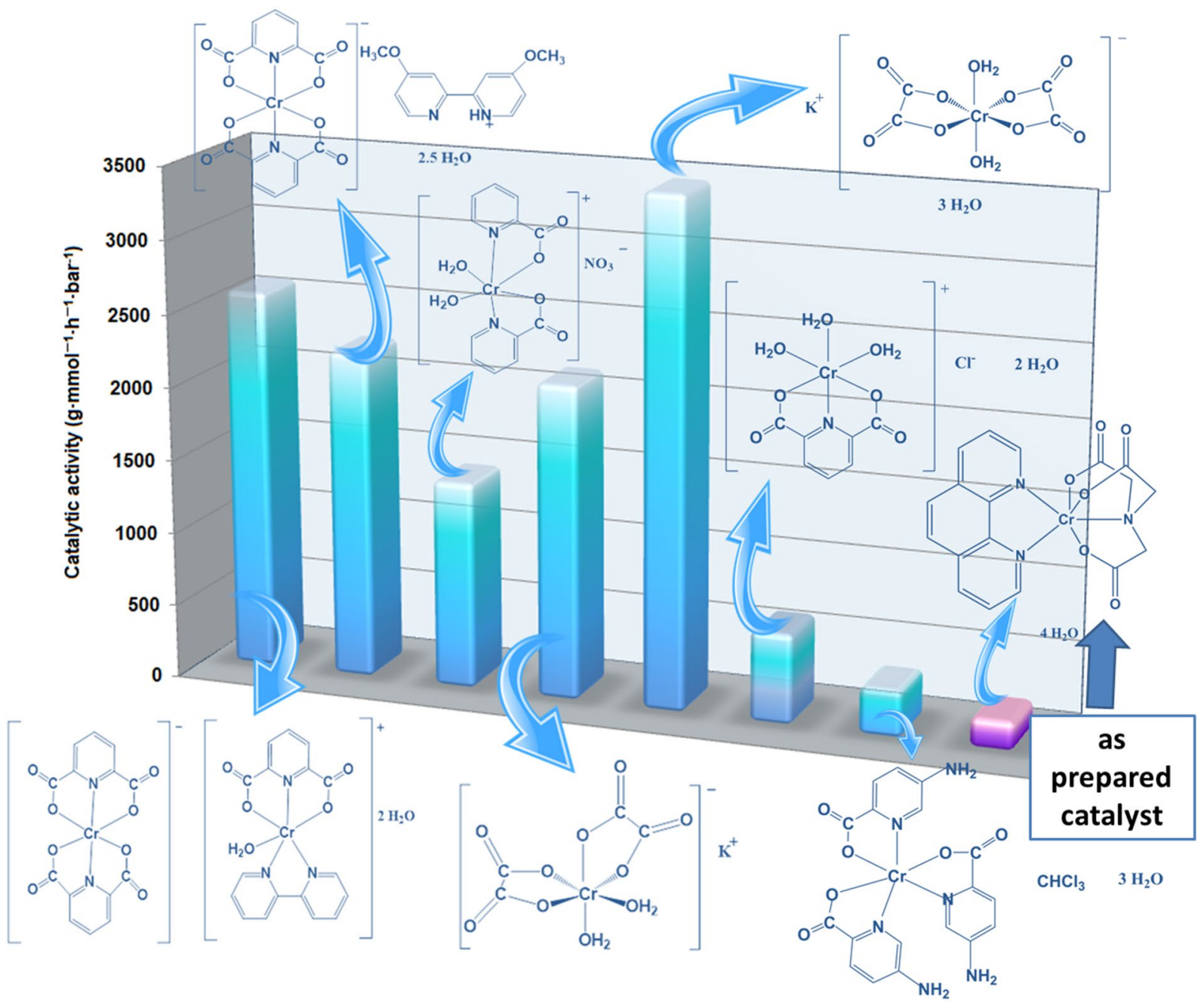

Figure 6. The catalytic activities of $\mathrm{Cr}$ (III) complexes for 2-chloro-2-propen-1-ol oligomerization based on ${ }^{36-40}$.

Ethylene oligomerization. A solution of precatalyst was prepared by dissolving $3 \mu \mathrm{mol}$ of Cat-CrNP in $2 \mathrm{~mL}$ of toluene in a glass tube on the magnetic stirrer. The oligomerization process was carried out at 0.12 bar, at room temperature and nitrogen atmosphere. In the next reaction stage, MMAO-12 (3 mL) solution was introduced. The solution was allowed to mix for a while, then ethylene was added all the time until the process was complete. The gel product was obtained after $15 \mathrm{~min}$ of the reaction. Then the formed product was dried and weighed.

Physico-chemical characterization. Diffraction data were collected on an Oxford Diffraction Gemini R ULTRA Ruby CCD diffractometer $\left(\mathrm{T}=295(2) \mathrm{K}, \mathrm{MoK}_{\alpha}(\lambda=0.71073 \AA)\right.$ radiation, Table 1 -see Electronic Supplementary Information) and were reduced using CrysAlis RED software (ver. 1.171.41.16a ${ }^{43}$. The structures were refined and solved using the SHELX package (ver. 2017/1) ${ }^{44}$. The water molecule including O4W atom has orientation disorders with refined site-occupancy factors equal 0.50(7). H-atoms from water molecules were located on a difference Fourier map and refined with restraints (DFIX command) with $d_{(\mathrm{O}-\mathrm{H})}=0.95 \AA$ and $\mathrm{U}_{\text {iso }}(\mathrm{H})=1.5 \mathrm{U}_{\text {eq }}(\mathrm{O})$, while $\mathrm{H}$-atoms bound to $\mathrm{C}$-atoms were placed geometrically and refined using a riding model with $d_{(\mathrm{C}-\mathrm{H})}=0.93-0.97 \AA$ and $\mathrm{U}_{\text {iso }}(\mathrm{H})=1.2 \mathrm{U}_{\mathrm{eq}}(\mathrm{C})$. All interactions were identified using the PLATON program (ver. 181,115$)^{45}$.

The ORTEPII, PLUTO-78 and Mercury (ver. 2020.2.0) programs were used to prepare the molecular graphics $^{46-48}$. A disordered part of the O4W water molecule was omitted from the figures, for clarity. Full crystallographic details for title compound have been deposited in the Cambridge Crystallographic Data Center (deposition No. CCDC 2,058,007) and they may be obtained from www: http://www.ccdc.cam.ac.uk, e-mail: deposit@ccdc.cam.ac.uk or The Director, CCDC, 12 Union Road, Cambridge, CB2 1EZ, UK.

The elemental analysis of Cat-CrNP was examined by performed on the Vario EL analyzer Cube (CHNS). MALDI-TOF-MS was carried out for Cat-CrNP and for the oligomerization products using the BrukerBiflex III spectrometer. 2,5-Dihydroxybenzoic acid was the matrix used during the recording of spectra. IR spectra were recorded ranging from 4000 to $600 \mathrm{~cm}^{-1}$ in $\mathrm{KBr}$ pastil (BRUKER IFS 66 spectrophotometer). Potentiometric titration was performed using the CerkoLab system $(T=298.15 \mathrm{~K} \pm 0.10 \mathrm{~K}$ Lauda E100 circulation thermostat), 
Hamilton syringes $(5 \mathrm{~mL})$, a measuring cell and a combined $\mathrm{pH}$ electrode Schott Blue Line 16. Calibration of the electrode was carried out the weighing method. Titration systems were follows: (1) $\mathrm{H}_{3} \mathrm{NTA}(2 \mathrm{mM}),(2) \mathrm{Cr}^{3+}$ $(2 \mathrm{mM})+\mathrm{H}_{3} \mathrm{NTA}(2 \mathrm{mM}),(3) \mathrm{Cr}^{3+}(2 \mathrm{mM})+\mathrm{H}_{3} \mathrm{NTA}(2 \mathrm{mM})+$ phen $(2 \mathrm{mM})$, where $\mathrm{H}_{3} \mathrm{NTA}$-nitrilotriacetic acid, phen-1,10-phenantroline. A standard solution of $\mathrm{NaOH}(50 \mathrm{mM})$ was used as the titrant. The titrant was added every $60 \mathrm{~s}$ in an amount of $0.020 \mathrm{~mL}$. The each measurement consisted of 300 steps. Conductometric titration (CerkoLab equipment, a magnetic stirrer, a $5 \mathrm{ml}$ Hamilton's syringe) was carried out with a conductometric cell $\left(k=0.096 \mathrm{~cm}^{-1}\right.$ HYDROMET) at $298.15 \mathrm{~K} \pm 0.10 \mathrm{~K}$ (E100 Lauda circulation thermostat). The conductivity probe was calibrated using $\mathrm{KCl}$ solutions with conductivity of $84 \mu \mathrm{S}$ and $200 \mu \mathrm{S}$ purchased commercially from the Hamilton. $50 \mathrm{mM} \mathrm{NaOH}$ was applied as the titrant. The following systems were titrated: 1) $\mathrm{H}_{3} \mathrm{NTA}$ $\left.(2 \mathrm{mM}), 2) \mathrm{Cr}^{3+}(2 \mathrm{mM})+\mathrm{H}_{3} \mathrm{NTA}(2 \mathrm{mM}), 3\right) \mathrm{Cr}^{3+}(2 \mathrm{mM})+\mathrm{H}_{3} \mathrm{NTA}(2 \mathrm{mM})+$ phen $(2 \mathrm{mM})$. Thermal analysis (TG) was performed on NETZSCH TG 209 instrument in the temperature range from 0 to $1000^{\circ} \mathrm{C}$ in an argon atmosphere. The mass of samples subjected to thermal analysis was about $5 \mathrm{mg}$. The morphologies of the asprepared samples were investigated using field-emission SEM using JSM-7610F, JEOL. The differential scanning calorimetry (DSC) studies were performed using the equipment from Mettler Toledo in the range from - 150 to $500{ }^{\circ} \mathrm{C}$ with the heating rate of $10^{\circ} \mathrm{C} / \mathrm{min}$ in the inert atmosphere. The sample to the DSC measurements was about $5 \mathrm{mg}$. The calibration was carried out based on standards for thermal analysis (ind, n-octane). The liquid nitrogen was used to cooling.

Received: 26 February 2021; Accepted: 28 June 2021

Published online: 26 July 2021

\section{References}

1. Johnson, L. K., Killian, C. M. \& Brookhart, M. New Pd (II)-and Ni (II)-based catalysts for polymerization of ethylene and alphaolefins. J. Am. Chem. Soc. 117, 6414-6415 (1995).

2. Gao, J., Yang, B. \& Chen, C. Sterics versus electronics: Imine/phosphine-oxide-based nickel catalysts for ethylene polymerization and copolymerization. J. Catal. 369, 233-238 (2019).

3. Cui, L. \& Jian, Z. A N-bridged strategy enables hemilabile phosphine-carbonyl palladium and nickel catalysts to mediate ethylene polymerization and copolymerization with polar vinyl monomers. Polym. Chem. 11, 6187-6193 (2020).

4. Rizkin, B. A. \& Hartman, R. L. Supervised machine learning for prediction of zirconocene-catalyzed a-olefin polymerization. Chem. Eng. Sci. 210, 115224 (2019).

5. Kumawat, J., Trivedi, P. \& Gupta, V. K. Role of a multidentate carbonate Donor in $\mathrm{MgCl}_{2}$-supported Ziegler-Natta olefin polymerization catalysis: An experimental and computational approach. J. Phys. Chem. C. 123, 24501-24510 (2019).

6. McDaniel, M. P. A review of the Phillips supported chromium catalyst and its commercial use for ethylene polymerization. Adv. Catal. 53, 123-606 (2010).

7. Gibson, V. C. \& Spitzmesser, S. K. Advances in non-metallocene olefin polymerization catalysis. Chem. Rev. 103, 283-316 (2003).

8. Döhring, A. et al. Donor-ligand-substituted cyclopentadienylchromium(III) complexes: A new class of alkene polymerization catalyst. 1. Amino-substituted systems. Organometallics 19,388-402 (2000).

9. Huang, C. et al. A comparative kinetic study of ethylene polymerization mediated by iron, cobalt and chromium catalysts bearing the same N, N, N-bis(imino) trihydroquinoline. J. Catal. 369, 1-9 (2019).

10. Cooper, G. D. \& Floryan, D. E. 1977, U.S. Patent No. 4,039,510. Washington, DC: U.S. Patent and Trademark Office.

11. Cho, H. Y. et al. Synthesis of well-defined (nitrilotriacetic acid)-end-functionalized polystyrenes and their bioconjugation with histidine-tagged green fluorescent proteins. Macromolecules 44, 4672-4680 (2011).

12. Heredia, K. L. \& Maynard, H. D. Synthesis of protein-polymer conjugates. Org. Biomol. Chem. 5, 45-53 (2006).

13. Schmitt, L., Ludwig, M., Gaub, H. E. \& Tampe, R. A metal-chelating microscopy tip as a new toolbox for single-molecule experiments by atomic force microscopy. Biophys. J. 78, 3275-3285 (2000).

14. Hilbrig, F., Stocker, G., Schläppi, J. M., Kocher, H. \& Freitag, R. Utilization of group specific ligands in the downstream processing of proteins by affinity precipitation. Food Bioprod. Process. 84, 28-36 (2006).

15. Hart, C., Schulenberg, B., Diwu, Z., Leung, W.-Y. \& Patton, W. F. Fluorescence detection and quantitation of recombinant proteins containing oligohistidine tag sequences directly in sodium dodecyl sulfate-polyacrylamide gels. Electrophoresis 24, 599-610 (2003).

16. Schmid, E. L., Keller, T. A., Dienes, Z. \& Vogel, H. Reversible oriented surface immobilization of functional proteins on oxide surfaces. Anal. Chem. 69, 1979-1985 (1997).

17. Nicolas, J., Mantovani, G. \& Haddleton, D. M. Living radical polymerization as a tool for the synthesis of polymer-protein/peptide bioconjugates. Macromol. Rapid Commun. 28, 1083-1111 (2007).

18. Farber, E. M., Ojha, K., Burshtein, T. Y., Hasson, L. \& Eisenberg, D. Understanding the self-templating of hierarchically porous carbon electrocatalysts using Group 2 coordination polymers. Mat. Adv. 1, 20-33 (2020).

19. Liang, C., Hong, K., Guiochon, G. A., Mays, J. W. \& Dai, S. Synthesis of a large-scale highly ordered porous carbon film by selfassembly of block copolymers. Angew. Chem. Int. 43, 5785-5789 (2004).

20. Zhao, X. P. et al. Silica-templated covalent organic framework-derived Fe-N-doped mesoporous carbon as oxygen reduction electrocatalyst. Chem. Mater. 31, 3274-3280 (2019).

21. Serrano, J. M. et al. Composition design of block copolymers for porous carbon fibers. Chem. Mater. 31, 8898-8907 (2019).

22. Johnson, L. K., Killian, C. M. \& Brookhart, M. New Pd(II)-and Ni(II)-based catalysts for polymerization of ethylene and alphaolefins. J. Am. Chem. Soc. 117, 6414-6415 (1995).

23. Wang, F. \& Chen, C. A continuing legend: The Brookhart-type a-diimine nickel and palladium catalysts. Polym. Chem. 10, 2354-2369 (2019).

24. Wang, Z., Liu, Q., Solan, G. A. \& Sun, W. H. Recent advances in Ni-mediated ethylene chain growth: Nimine-donor ligand effects on catalytic activity, thermal stability and oligo-/polymer structure. Coordin. Chem. Rev. 350, 68-83 (2017).

25. Ye, Z., Xu, L., Dong, Z. \& Xiang, P. Designing polyethylenes of complex chain architectures via Pd-diimine-catalyzed "living" ethylene polymerization. Chem. Commun. 49, 6235-6255 (2013).

26. Small, B. L., Brookhart, M. \& Bennett, A. M. Highly active iron and cobalt catalysts for the polymerization of ethylene. J. Am. Chem. Soc. 120, 4049-4050 (1998).

27. Britovsek, G. J. P. et al. Novel olefin polymerization catalysts based on iron and cobalt. Chem. Commun. 7, 849-850 (1998).

28. Wang, Z., Solan, G. A., Zhang, W. \& Sun, W. H. Carbocyclic-fused N, N, N-pincer ligands as ring-strain adjustable supports for iron and cobalt catalysts in ethylene oligo-/polymerization. Coordin. Chem. Rev. 363, 92-108 (2018).

29. Bariashir, C., Huang, C., Solan, G. A. \& Sun, W. H. Recent advances in homogeneous chromium catalyst design for ethylene tri-, tetra-, oligo-and polymerization. Coordin. Chem. Rev. 385, 208-229 (2019). 
30. Baburao, B., Visco, D. P. Jr. \& Albu, T. V. Association Patterns in $(\mathrm{HF})_{m}\left(\mathrm{H}_{2} \mathrm{O}\right)_{n}(m+n=2-8)$ Clusters. J. Phys. Chem. A 111, 7940-7956 (2007).

31. Maeda, S. \& Ohno, K. Structures of water octamers $\left(\mathrm{H}_{2} \mathrm{O}\right)_{8}$ : Exploration on ab initio potential energy surfaces by the scaled hypersphere search method. J. Phys. Chem. A 111, 4527-4534 (2007).

32. Trzybiński, D. \& Sikorski, A. Solvent-bridged frameworks of hydrogen bonds in crystals of 9-aminoacridinium halides. CrystEngComm 15, 6808-6818 (2013).

33. Zhang, X. H. et al. Selective copolymerization of carbon dioxide with propylene oxide catalyzed by a nanolamellar double metal cyanide complex catalyst at low polymerization temperatures. Polymer 52, 5494-5502 (2011).

34. Qiang, L., Zhifang, G., Lisha, P. \& Xue, X. Zn-Cr double metal cyanide catalysts synthesized by ball milling for the copolymerization of $\mathrm{CO}_{2}$ /propylene oxide, phthalic anhydride/propylene oxide, and $\mathrm{CO}_{2}$ /propylene oxide/phthalic anhydride. Catal. Commun. 64, 114-118 (2015).

35. Malinowski, J., Jacewicz, D., Gawdzik, B. \& Drzeżdżon, J. New chromium (III)-based catalysts for ethylene oligomerization. Sci. Rep. 10, 16578 (2020).

36. Drzeżdżon, J., Sikorski, A., Chmurzyński, L. \& Jacewicz, D. New type of highly active chromium(III) catalysts containing both organic cations and anions designed for polymerization of beta-olefin derivatives. Sci. Rep. 8, 2315 (2018).

37. Drzeżdżon, J., Sikorski, A., Chmurzyński, L. \& Jacewicz, D. Oligomerization of 2-chloroallyl alcohol by 2-pyridinecarboxylate complex of chromium (III)-new highly active and selective catalyst. Sci. Rep. 8, 8632 (2018).

38. Drzeżdżon, J., Chmurzyński, L. \& Jacewicz, D. Geometric isomerism effect on catalytic activities of bis(oxalato)diaquochromates(III) for 2-chloroallyl alcohol oligomerization. J. Chem. Sci. 130, 116 (2018).

39. Drzeżdżon, J. et al. Formation of 2-chloroallyl alcohol oligomers using a new crystalline dipicolinate complex of $\mathrm{Cr}$ (III) as a catalyst. J. Catal. 375, 287-293 (2019).

40. Malinowski, J., Sikorski, A., Jacewicz, D. \& Drzeżdżon, J. A new complex compound of chromium (III) with 5-aminopyridine2-carboxylate anions-structure, physicochemical and catalytic properties. Polyhedron 186, 114616 (2020).

41. Boudier, A., Breuil, P. A. R., Magna, L., Olivier-Bourbigou, H. \& Braunstein, P. Ethylene oligomerization using iron complexes: Beyond the discovery of bis (imino) pyridine ligands. Chem. Commun. 50, 1398-1407 (2014).

42. Liu, F. S. et al. Nickel complexes bearing $[\mathrm{N}, \mathrm{N}] 2$-pyridylbenzamidine ligands: Syntheses, characterizations, and catalytic properties for ethylene oligomerization. Polyhedron 28, 1386-1392 (2009).

43. CrysAlis CCD and CrysAlis RED; Version 1.171.36.24; Oxford Diffraction Ltd.: Yarnton, UK (2012).

44. Sheldrick, G. M. Crystal structure refinement with SHELXL. Acta Cryst. C 71, 3-8 (2015).

45. Spek, A. L. Structure validation in chemical crystallography. Acta Cryst. D 65, 148-155 (2009).

46. Johnson, C. K. ORTEP II, Report ORNL-5138 (Oak Ridge National Laboratory, Oak Ridge, 1976).

47. Motherwell, S. \& Clegg, S. PLUTO-78, Program for Drawing and Molecular Structure (University of Cambridge, 1978).

48. Macrae, C. F. et al. Mercury CSD 2.0-new features for the visualization and investigation of crystal structures. J. Appl. Crystallogr. 41, 466-470 (2008).

\title{
Acknowledgements
}

Supported by the Foundation for Polish Science (FNP).

\section{Author contributions}

Conceptualization: J.D., D.J.; Methodology: J.D., D.J.; Investigation: J.M., M.U., P.R., B.G., A.S., P.P; Writingoriginal draft preparation: J.D., D.J., J.M., A.S., A.Z.-M.; Supervision: J.D., D.J., A.Z.-M.; Funding acquisition: B. G. All authors have read and agreed to the published version of the manuscript.

\section{Competing interests}

The authors declare no competing interests.

\section{Additional information}

Supplementary Information The online version contains supplementary material available at https://doi.org/ 10.1038/s41598-021-94056-0.

Correspondence and requests for materials should be addressed to B.G.

Reprints and permissions information is available at www.nature.com/reprints.

Publisher's note Springer Nature remains neutral with regard to jurisdictional claims in published maps and institutional affiliations.

\begin{abstract}
Open Access This article is licensed under a Creative Commons Attribution 4.0 International License, which permits use, sharing, adaptation, distribution and reproduction in any medium or format, as long as you give appropriate credit to the original author(s) and the source, provide a link to the Creative Commons licence, and indicate if changes were made. The images or other third party material in this article are included in the article's Creative Commons licence, unless indicated otherwise in a credit line to the material. If material is not included in the article's Creative Commons licence and your intended use is not permitted by statutory regulation or exceeds the permitted use, you will need to obtain permission directly from the copyright holder. To view a copy of this licence, visit http://creativecommons.org/licenses/by/4.0/.
\end{abstract}

(C) The Author(s) 2021 